\title{
A dinâmica dos gastos estatais numa perspectiva marxista clássica
}

José Raimundo Barreto Trindade ${ }^{1}$

\begin{abstract}
Resumo: Este artigo busca demonstrar que o Estado capitalista se estrutura e se modifica com a dinâmica reprodutiva do capital, expandindo os gastos estatais em conformidade com o processo de acumulação e crise do sistema. Para isso desenvolvemos num primeiro momento, o entendimento histórico e lógico do Estado capitalista sob a percepção de obras clássicas de Marx, Engels e autores marxistas, proporcionando elementos analíticos para o entendimento da dinâmica dos gastos estatais. No item seguinte faz-se a interligação entre a compreensão do Estado e seu desenvolvimento histórico e por último, esmiúça-se o padrão dos gastos estatais modernos.
\end{abstract}

Palavras-chave: Estado; gastos estatais; Marx.

\section{The dynamics of the state expenses in a classic marxist view}

\begin{abstract}
This article attempts to demonstrate that the capitalist State structures and modifies itself with the reproductive dynamics of the capital, expanding the state expenses in compliance with the accumulation process and crisis of the system. For this we develop first the historical and logical understandings of the capitalist State under the perception of classic works of Marx, Engels and marxist authors, providing analytical elements for the understanding of the dynamics of state expenses. In what follows there is an attempt to link this view of the State
\end{abstract}

1 Professor Adjunto da Universidade Federal do Pará; Doutor em Desenvolvimento Econômico pela Universidade Federal do Paraná. E-mail: jrtrindade@uol.com.br 
and its historical development and finally, the standard of the modern state expenses.

Keywords: State; state expenses; Marx.

JEL: $\mathrm{H} 5$

Introdução

O Estado como uma forma geral de poder político ${ }^{2}$ assume a capacidade organizativa política e institucional dos interesses do capital enquanto classe. Esta noção do Estado, enquanto poder de classe é ponto de partida para o entendimento genérico do Estado, na medida em que diversas outras formas sociais de reprodução ao longo da história foram também baseadas na expropriação do excedente socialmente produzido em favor de uma classe social específica e teve na forma estatal um poder político de domínio de classe. Assim a análise do Estado capitalista requer a necessária interação com a lógica de acumulação própria desse sistema.

Para dar conta da análise específica do Estado capitalista deve-se relacioná-lo ao que aqui denominamos de elemento básico de sua identidade, ou seja, sua função de controle social vinculada à manutenção e regularidade da relação salarial e suas funções auxiliares ao sistema de reprodução capitalista. Nesse sentido partimos do entendimento que o capitalismo é uma forma cumulativa de riqueza que se assenta na permanente conversão de capital-dinheiro em capital produtivo, tendo como pressuposto a generalidade da força de trabalho enquanto mercadoria e a contínua e regular troca de trabalho vivo por trabalho morto, forma econômica que se materializa em uma relação contratual: a relação salarial.

Este artigo busca demonstrar que o Estado capitalista se estrutura e se modifica com a dinâmica reprodutiva do capital, expandindo os gastos estatais em conformidade com o processo de acumulação e crise do sistema. Para isso desenvolvemos num primeiro momento, o entendimento histórico e lógico do Estado capitalista sob a percepção de obras clássicas de Marx, Engels e autores marxistas, proporcionando elementos analíticos para o entendimento da dinâmica dos gastos estatais. No item seguinte faz-se a interligação entre a compreensão do Estado e seu desenvolvimento histórico e por último, esmiúça-se o padrão dos gastos estatais modernos.

2 Esta concepção comparece já nas primeiras análises e escritos de Marx e Engels, como por exemplo, a "Ideologia Alemã" de 1845 , obra na qual antecipam o método de crítica que será utilizado para analisar a economia política clássica. Pode-se denominar esta percepção do Estado capitalista como de fundo "marxista clássico" como entendem Carnoy (1986) e Jessop (1982). 


\section{A Derivação histórica e lógica do estado capitalista}

No capitalismo, a relação capital é a de apropriação da mais-valia fundada em relações contratuais entre o capitalista (comprador da mercadoria força de trabalho) e o trabalhador (vendedor da mercadoria força de trabalho). Entre eles trava-se uma troca de equivalentes no processo de circulação de mercadorias: a força de trabalho, mercadoria que é a única propriedade do trabalhador, é comprada pelo capitalista, que oferece em troca a forma monetária salário, o preço da mercadoria força de trabalho. Essa aparente igualdade na forma do trato jurídico torna a relação salarial condição central tanto da reprodução econômica do sistema, quanto da sua configuração política.

A condição para essa pretensa igualdade é a universalização formal da propriedade e a generalização da força de trabalho como mercadoria, aspecto histórico-lógico central para o capitalismo. Ao definir-se como aspecto histórico-lógico não se considera a relação assalariada uma especificidade somente do capitalismo, pois mesmo em sociedades précapitalistas comparecem formas subordinadas de assalariamento. A especificidade do capitalismo é que esta é a primeira forma histórica com a generalização de relações contratuais de trabalho, e sob o ponto de vista lógico essa forma relacional é determinante na produção do excedente social (mais-valia).

A forma salário é a condição econômica mais importante para o desenvolvimento das relações jurídicas burguesas ${ }^{3}$, na medida em que o estabelecimento definitivo de relações contratuais que na forma guardam a igualdade de contraposição entre indivíduos portadores de valor de troca semelhantes, cuja disponibilidade do valor de uso para o intercâmbio se dá na forma de mercadoria, confere ao capitalismo e à expropriação da mais-valia uma aparente legitimidade universal.

A força legitimadora das relações de produção capitalistas não está centrada exclusivamente em fatores de coerção que são primazia do Estado, mas também na pretensa legitimidade conferida ao processo de apropriação da mais-valia pela "mistificação" fruto da relação salarial. Deste modo, todos os "agentes econômicos" comparecem no mercado como proprietários de mercadorias, portadores de um valor de troca equivalente. Esta configuração econômica estabelece uma identidade que fundamenta a consciência jurídica e a especificidade do poder estatal capitalista.

3 "A troca entre capital e trabalho apresenta-se de início à percepção como absolutamente igual à compra e venda das outras mercadorias. O comprador dá determinada quantia em dinheiro, o vendedor um artigo diferente de dinheiro. A consciência jurídica reconhece aí no máximo uma diferença material que não altera a equivalência das fórmulas: Dou para que dês, dou para que faças, faço para que dês, faço para que faças (do ut des, do ut facias, facio ut des, facio ut facias)" (Marx, OCI, 1987:623). 
O Estado cumpre deste modo, a função central de controle e legitimação da ordem capitalista, principalmente ao encobrir as relações de apropriação da mais-valia e justificando positivamente a propriedade privada dos meios de produção, sob a forma de aparente universalidade e igualdade dos direitos de propriedade. Como agente central para manutenção das relações capitalistas de produção, o Estado encobre parcialmente o conflito latente existente na relação capital-trabalho e, ao mesmo tempo, legitima a relação de exploração, por meio da imposição das regras positivas do direito de propriedade burguês.

Por outro lado, a relação salarial é antes de tudo uma relação monetária, estabelecendo-se a equalização entre um quantum de valor universal - equivalente geral - que na forma dinheiro assume a qualidade de capital variável, passível de adquirir a mercadoria força de trabalho. Nessa relação estão envolvidos dois tipos especiais de mercadorias (De Brunhoff 1977,1978 ), cuja determinação do sistema de produção capitalista está na dependência da completa generalização de suas formas em termos sociais como mercadorias apropriadas pelo capital e tornadas meios necessários à acumulação capitalista: a força de trabalho e o dinheiro.

O dinheiro como uma relação social interna ao sistema tem sua reprodução decorrente da acumulação capitalista e, ao mesmo tempo, sendo necessário para que esta se processe. A endogenia do dinheiro enquanto elemento central da teoria marxista integra-se à dinâmica de acumulação e se constitui enquanto forma estrutural do capital, ao lado da mercadoria força de trabalho. Cabe ao Estado a importante função de regular essas duas relações especiais (salarial e monetária), circunscritas às leis gerais de movimento da dinâmica capitalista.

$\mathrm{O}$ uso da força de trabalho social pelos capitalistas requer a regulamentação jurídica cujo agente regulamentar tem que ser portador da "consciência coletiva" dos capitais, ou seja, o Estado capitalista. A mercadoria força de trabalho é um problema coletivo dos capitais, cabendo ao Estado enquanto agente coletivo dos mesmos, dispor juridicamente sobre o seu uso social. Esse processo institucional de regulamentação do uso coletivo da força de trabalho social, pelos capitais, constitui o processo de gestão da mesma por parte do Estado. ${ }^{4}$

4 Marx trata no primeiro tomo de "O Capital" das chamadas "Leis Fabris", onde demonstra que a intervencão estatal é necessária para fazer frente aos interesses "predatórios" de frações da classe capitalista, funcionando o Estado conforme os interesses do capital "como um todo" (cfe. Marx 1987, e para uma discussão atual, Fine \& Harris 1981 e Figueiredo 2003). 


\section{Reprodução econômica e reprodução social}

O modo de produção capitalista leva a uma reorganização da sociedade, assentado sob uma forma peculiar de exploração cuja dinâmica de produção e apropriação da mais-valia requer não formas de coerção direta, mas relações de subordinação baseadas em formas contratuais. Essas relações contratuais, seja o assalariamento - como forma principal sejam as diversas formas de contratos celebrados entre capitais, pressupõem a cessão da posse da mercadoria entre os dois contratantes, o que não implica cessão da propriedade, porém o uso conveniente e lucrativo da coisa cedida.

Deste modo, o entendimento da "igualdade jurídica" formal no capitalismo é aspecto central para a compreensão da existência e atuação do Estado moderno capitalista, diferentemente das formas sociais anteriores que se baseavam em expropriação compulsória do excedente, como no escravismo, ou, de forma mais velada, na servidão, cuja base da diferenciação social inscreve-se tanto no estatuto da posse sobre a propriedade como também no reconhecimento hierárquico dos indivíduos com base em privilégios consuetudinários. Assim, a distinção entre esfera pública e esfera privada alcança sua forma mais desenvolvida no capitalismo.

O Estado moderno surge, portanto, como decorrência direta da subordinação de toda e qualquer outra esfera humana à esfera econômica. As relações com base em privilégios nas sociedades pré-capitalistas se transmutam em definitivo para relações com base unicamente no direito de propriedade, sendo o Estado uma forma de representação e manutenção desses direitos. Sua função central será a de garantir a perenidade das relações salariais, não se admitindo questionamento quanto à posse do excedente social produzido e sua atuação poderá ser tanto regulamentadora de tais relações, como fazendo uso dos atributos repressivos que lhe são socialmente delegados pelo poder do capital.

Do mesmo modo, as finanças necessárias à sua manutenção deixaram de ser finanças privadas (patrimoniais e do soberano) e passaram a ser finanças públicas (patrimoniais, porém da classe mantenedora e dominante), cuja capacidade de custeio das diferentes funções que exerce deriva-se dos ciclos perpétuos de acumulação, cota parte subtraída da mais-valia social e destinada à garantia deste capitalista coletivo.

A reprodução econômica da sociedade necessariamente terá que assegurar a sua reprodução social. Assim a manutenção dos interesses de classe tem como ponto de sustentação financeira o excedente produzido e distribuído. Essa distribuição da riqueza líquida produzida (maisvalia) se dá de acordo com as condições de manutenção e desenvolvi- 
mento do sistema de produção capitalista. O Estado capitalista é um dos agentes sociais que se apropria de uma parcela da riqueza líquida social e a parcela da mais-valia a ele destinada compreende a receita necessária às despesas de reprodução social que se encontram sob sua responsabilidade.

Podemos resumir os seguintes aspectos centrais do entendimento sobre o Estado aqui esboçado 5 :

i) A reprodução econômica é a base necessária à afirmação da estrutura social e das consciências individuais, a sociedade se molda pelo modo dominante de produção e das relações de produção inerentes a esse modo.

ii) o Estado é uma forma resultante do conflito de classes, inerente às sociedades que, ao alcançarem certo nível de desenvolvimento das relações de produção e definidas por um padrão de apropriação privada da riqueza social, requerem um agente de defesa dos interesses da classe proprietária. Esse entendimento se contrapõe frontalmente à noção de Estado neutro ou curador dos interesses comuns da coletividade, dominante nas versões liberais que fundamentam as teorias de finanças públicas.

iii) Um terceiro aspecto diz respeito ao papel repressivo do Estado, tanto na forma de poder de polícia capaz de assegurar o direito privado de propriedade, frente a qualquer possível questionamento interno; quanto o poder militar que assegura, sejam as condições internas de acumulação e reprodução social frente a qualquer outro poder de Estado exterior ou, sob o ponto de vista imperialista, a possibilidade de expansão econômica e acesso a fontes de recursos necessários ao processo de acumulação capitalista.

iv) O Estado capitalista é uma forma orgânica do capital, componente necessário ao processo de reprodução social do mesmo, cumprindo funções políticas centrais, como as de legitimação ideológica e de controle social, porém irremediavelmente vinculadas às funções econômicas que atuam integradas ao processo de acumulação e reprodução econômica.

5 Para uma exposição comparativa detalhada das diferenciadas interpretações marxistas do Estado conferir Carnoy (1986). Barrow (2000:113) propôs um quadro analítico de diferentes esquemas teóricos apoiados em distintos estudos de Marx e Engels, consideramos nesta breve exposição somente três desses núcleos de construção: instrumentalismo (Milimband), estruturalismo (Poulantzas) e derivacionismo (Hirsch e Schäfer). Outros dois núcleos de desenvolvimento teóricos é a chamada "análise sistêmica" (Luhmann) e o "realismo organizacional" (Skocpol), cujo desenvolvimento metodológico não satisfaz nossas necessidades expositivas quanto ao objetivo central deste trabalho que é o de construção de elementos analíticos para o entendimento da divida pública em Marx. 
v) O Estado desempenha, ao lado das funções de controle e legitimação do domínio de classe, funções gerais necessárias à reprodução do coletivo social, muitas das quais de natureza técnica, como atividades administrativas vinculadas ao desenvolvimento social em sua totalidade (seguridades sociais, educacionais, etc.).

vi) Convém, finalmente, observar que a análise do Estado capitalista em geral, necessariamente tem que ser complementada pela sua concretização em termos de Estado nacional. O Estado moderno vincula-se as condições de acumulação capitalista nacional, que determina os limites da receita fiscal, ao lado das condições de atração de fundos que financiam a expansão de sua dívida pública.

\section{A dinâmica dos gastos estatais}

Os gastos estatais são crescentes ao longo das fases históricas do modo de produção capitalista, o que se convencionou denominar de lei de Wagner. ${ }^{6}$ A complexidade do sistema de reprodução capitalista ${ }^{7}$ explica parcialmente os gastos crescentes, isso por conta, que uma das principais rubricas dos gastos estatais se refere ao que se convencionou denominar de infra-estrutura econômica e social e a manutenção de instituições destinadas à gestão desses gastos.

Na medida em que as relações mercantis se generalizam, uma parcela importante de atividades que demandam parcela da receita estatal passa a ser efetuada por unidades capitalistas de produção, porém mantém-se sempre setor não passível de capitalização e, por outro, novos setores de baixa rentabilidade são periodicamente criados e assumidos pelo Estado. Deve-se assinalar ainda, que as permanentes irrupções de crises no sistema capitalista, forçam uma presença crescente do Estado na gestão de determinados setores da economia desobstruindo pontos de entrave à acumulação de capital. Crescem também os gastos neces-

\footnotetext{
6 Adolph Wagner foi um economista alemão de fins do século XIX, o enunciado do que se convencionou denominar de lei dos gastos públicos crescentes corresponde a observações empíricas e estatísticas comparadas realizadas pelo autor. O enunciado a seguir é retirado de Taylor (1960:11): "Las amplias comparaciones entre países diferentes y en momentos distintos, muestran que entre los pueblos progresivos (...), tiene lugar regularmente un aumento en la actividad, tanto del Gobierno central como de los locales (...)".

7 Foley (1990:301) considera que existem sob o ponto de vista marxista duas explicações para a moderna expansão do Estado. A primeira seria decorrente dos movimentos de concentração e centralização dos capitais que ao desenvolverem grandes corporações, também levou a um "gigantismo" do Estado, em função da crescente necessidade de recursos para fazer frente aos conflitos entre "grandes e pequenos capitais". A segunda explicação refere-se ao crescimento dos gastos estatais em correspondência a severidade das crises capitalistas, atuando o Estado como principal agente estabilizador do sistema.
} 
sários a processos de controle social interno (ou seja, referente a cada formação social nacional), em particular, o que diz respeito à manutenção de forças de coerção e de segurança estritamente interna. ${ }^{8}$

As despesas bélicas e manutenção de forças militares mais estruturadas e ativas em períodos de tempo cada vez maiores é outro fator responsável pelo crescente esforço fiscal e endividamento do Estado. O chamado complexo "industrial-militar" é uma das rubricas centrais da pressão orçamentária dos principais Estados capitalistas modernos, sendo sua principal forma de financiamento a dívida estatal.

Por outro lado, também se elevam as despesas vinculadas ao processo de legitimação social, o que, como vimos, tem sua base na relação salarial e que requer renovados processos de adaptação, como mudanças em regimes salariais, políticas previdenciárias e de saúde pública, ocasionando a manutenção de instituições necessárias a dar suporte a esses processos. Estão inclusos nesses "gastos sociais" aqueles recursos destinados ao que Marx (1985:202) na "Crítica ao Programa de Gotha", denominou de "satisfação de necessidades coletivas", tais como escolas, instituições sanitárias, etc.

Deve-se considerar ainda a capacidade organizativa e de luta dos trabalhadores fator importante na configuração da estrutura orçamentária geral dos gastos governamentais, podendo ser considerados dois elementos destes gastos que sofrem influência direta da luta de classes: i) recursos destinados à satisfação de necessidades coletivas, tais como escolas, instituições sanitária e de saúde pública, etc.; e ii) os fundos de manutenção das pessoas não capacitadas para o trabalho, tais como previdência social e seguridade social.

A seguir detalhamos os gastos estatais, estruturando sua composição de forma genérica, o que nos possibilitará no passo seguinte, estabelecer uma primeira aproximação entre a despesa estatal e a receita pública.

\footnotetext{
8 Engels (2002:203-04) estabeleceu esse item enquanto traço marcante do Estado em geral: "O segundo traço característico [do Estado] é a instituição de uma força pública, que já não mais se identifica com o povo em armas. A necessidade dessa força pública especial deriva da divisão da sociedade em classes, que impossibilita qualquer organização espontânea da população (...) Essa força pública existe em todo Estado; é formada não só de homens armados como, ainda, de acessórios materiais, os cárceres e as instituições coercitivas de todo gênero"
} 


\section{QUADRO I - FUNÇÕES E GASTOS DO ESTADO CAPITALISTA}

\begin{tabular}{|c|c|c|c|}
\hline FUNÇOES & ESPECIFICIDADE & TENDÊNCIA & FINANCIAMENTO \\
\hline $\begin{array}{l}\text { a)Funções gerais } \\
\text { a1 -necessidades coletivas } \\
\text { a2 - necessidades técnicas gerais }\end{array}$ & $\begin{array}{l}\text { Necessárias ao } \\
\text { desenvolvimento do } \\
\text { coletivo social }\end{array}$ & $\begin{array}{l}\text { Pressão para diminuir conforme as } \\
\text { condições estruturais do processo de } \\
\text { acumulação e melhora tecnológica e } \\
\text { capacidade organizacional, contrapondo- } \\
\text { se a tendência histórica a aumentar. }\end{array}$ & Receita fiscal. \\
\hline $\begin{array}{l}\text { b) Função técnica especifica do } \\
\text { capitalismo }\end{array}$ & $\begin{array}{l}\text { Necessidades técnicas } \\
\text { específicas do } \\
\text { capitalismo } \\
\text { (administrativas, } \\
\text { reguladoras da } \\
\text { concorrência entre } \\
\text { capitais, fiscais e } \\
\text { monetárias). }\end{array}$ & $\begin{array}{l}\text { Aumentam conforme o sistema } \\
\text { torna-se mais centralizado e } \\
\text { globalizado. }\end{array}$ & $\begin{array}{l}\text { Receita fiscal } \\
\text { principalmente, mas } \\
\text { também } \\
\text { "senhoriagem" e divida } \\
\text { estatal } \\
\text { secundariamente } \\
\text { (como técnica } \\
\text { monetária. }\end{array}$ \\
\hline c)Controle e legitimação & & $\begin{array}{l}\text { Crescente ao longo do desenvolvimento } \\
\text { do capitalismo. }\end{array}$ & $\begin{array}{l}\text { Receita fiscal } \\
\text { principalmente. }\end{array}$ \\
\hline d) Bélicos e Militares & & $\begin{array}{l}\text { Crescente ao longo do desenvolvimento } \\
\text { do capitalismo. }\end{array}$ & $\begin{array}{l}\text { Divida estatal } \\
\text { principalmente. }\end{array}$ \\
\hline
\end{tabular}

\section{Gastos estatais destinados a beneficiar o capital social}

A intervenção estatal em importantes setores inclusive rentáveis se vincula em termos gerais as condições sociais necessárias à reprodução do capital. O termo geral se refere à consecução de atividades indispensáveis para o conjunto da burguesia, por exemplo: pesquisa, fornecimento de insumos energéticos estáveis, comunicações e infra-estrutura viária.

O termo capital social foi definido por Marx (OCII, 1987:99) enquanto o "movimento global do capital", sendo expresso pela soma dos capitais individuais, se inclui nesta totalidade os capitais das sociedades anônimas, algo que se tornou majoritário no capitalismo contemporâneo e os capitais do Estado, "quando este funciona como capitalista industrial, empregando trabalho assalariado em minas, ferrovias etc". ${ }^{9}$ Será desconsiderada a possível receita que o Estado poderia obter explorando empresarialmente setores da economia, isto por conta do entendimento prévio de que as empresas estatais podem ser consideradas como unidades de produção componentes dos setores produtores de meios de consumo e meios de produção.

Apesar de ainda hoje nas principais economias capitalistas se observar uma grande participação do Estado em diversos setores, seja de serviços ou industriais, a tendência do sistema é de que as condições gerais

\footnotetext{
9 Marx (OCII, 1987:99) pondera ainda que o capital social mesmo fosse a resultante do somatório dos capitais individuais não impossibilita que o "movimento do capital individual isolado manifeste fenômenos diferentes dos apresentados pelo mesmo movimento, quando considerado parte do movimento global do capital social, portanto em sua conexão com os movimentos das outras partes desse capital, nem que o movimento global resolva problemas cuja solução tem de ser pressuposta quando se estuda o ciclo de um capital individual".
} 
do processo social de produção passem a se nutrir do capital enquanto capital e não mais dos rendimentos sociais, dos impostos estatais, o que revela o grau crescente de mercantilização da sociedade, transformando-se em processos de capitalização todas as formas de necessidades humanas, "inclusive as necessidades do indivíduo que são estatuídas socialmente" (Marx apud Schäfer 1990:123).

Essa tendência apontada por Marx está sujeita às variações conjunturais e a fortes modificações conforme se imponham eventuais necessidades em função de crises agudas ou recuperação econômica do sistema. Schäfer (1990:123) observa que o Estado pode coagir a sociedade a desembolsar uma parte de sua receita em benefício daqueles trabalhos públicos que aparecem como condições gerais de produção e não como condições especiais de algum capitalista em particular, onde a vantagem imediata, isto é, a expectativa de lucro proveniente do comando capitalista for irrisória ou indeterminada, o capital pode transferir as despesas necessárias para o Estado, a fim de que estas venham a ser pagas pelo fundo fiscal, que é necessariamente um fundo comum da classe. Deve-se ponderar que os ganhos de gestão coletiva, atuando o Estado como ponto de apoio comum e necessário à reprodução social do capital, oferece vantagens na economia de recursos vis-à-vis a gestão particular por parte dos diferentes capitais isolados.

$\mathrm{O}$ volume e características do orçamento estatal influenciam diferentes segmentos do capital e produzem fluxos e refluxos de capital-dinheiro. Na medida em que o Estado se compromete com gastos e privilegia determinados capitais em detrimento de outros e, do mesmo modo, atua, via política fiscal - carga tributária e gasto governamental - e sistema de dívida pública - emissão de títulos, pagamento de juros e amortização de dívida.

O Estado desenvolve atividades adquirindo meios de consumo do departamento II da economia, na forma de bens salários adquiridos pelos funcionários públicos e adquire bens de produção do DI, trocando-se diretamente renda do Estado por parcela da produção daqueles departamentos.

Esses gastos estatais destinam-se a suprir a infra-estrutura física necessária ao desenvolvimento das atividades econômicas e também de reprodução social, sendo parcela da infra-estrutura econômica necessária à acumulação, como os sistemas rodoviários de transportes, sistema energético e de eletrificação e a estrutura sanitária e de fornecimento de água. A infra-estrutura social necessária tanto ao desenvolvimento das condições de reprodução capitalista quanto ao suprimento das necessidades coletivas sociais em geral é o que denominamos de fundo patrimonial público, componente importante das despesas do Estado. 
O fundo patrimonial público (fpp) resulta do conjunto dos gastos necessários ao cumprimento das funções gerais imprescindíveis a reprodução do capital, compondo parcela considerável da infra-estrutura física e material das sociedades modernas, tendo características de bens públicos, ou seja, valores de uso que estão impossibilitados de se mercantilizar convencionalmente em função de suas características de uso coletivo, como parques, rodovias e instalações de saneamento. Neste sentido, deve-se considerar que em quase todas as rubricas de gastos estatais incluem-se elementos desse "fundo de consumo social", sejam rodovias, aeroportos, escolas, hospitais, prédios de assistência pública, estrutura urbana, etc.

Esse fundo se assemelha em termos formais ao capital fixo, isso porque seu desgaste se dá aos poucos e funciona como "instrumento de consumo" (Harvey 1990:234), como no caso do fornecimento de serviços, como os de água e eletricidade, que exigem grandes investimentos iniciais, elevados custos de produção e "taxas de retorno" muito baixas, o que impossibilita, pelo menos temporariamente, a exploração capitalista, sendo assumida pelo Estado e financiada no médio e longo prazo principalmente via dívida pública. ${ }^{10}$

\section{Gastos estatais destinados à legitimação do sistema e ao controle social}

A configuração capitalista baseada no capital por ações e nos grandes conglomerados oligopolistas apresenta uma coesão econômica que se materializa em forte unidade na intervenção política. Segundo Hilferding (1985:318) "a cartelização unifica o poder econômico e eleva assim diretamente sua eficácia política”, o que culminaria na capacidade superior do Estado capitalista de confrontar parcialmente as condições de crise da dinâmica de acumulação, mas também, acomodar interesses de outras frações de classe.

Acomodação de interesses não significa de modo algum uma pretensa condição autônoma do Estado em relação às classes sociais, e sim conseqüência de modificações pontuais nas relações estruturais que compõem o sistema, sobre as quais o Estado age enquanto força reguladora. Deste modo pode-se lembrar que as mudanças em torno da regulamentação da relação salarial no pós-guerra, nas principais economias capitalistas, foi muito mais resultado da pressão dos movimentos de traba-

10 Deve-se observar que o "patrimônio público" pode ser privatizado e tornar-se parte do capital social, o que é bastante normal na história do capitalismo. Na atual fase de "globalização" do capital, a privatização de "ativos" reais, principalmente empresas vinculadas ao suprimento de infraestrutura social, como energia elétrica e telecomunicações, foi uma tônica na retomada do ciclo de expansão da acumulação, neste sentido é bastante interessante à análise de Duménil \& Lévy (2003). 
lhadores e da conjuntura peculiar das décadas de 40 e 50 , do que propriamente das maiores ou menores intervenções do Estado keynesiano.

Nada leva a crer que as modificações pontuais ocorridas tenham alterado a estrutura da relação de exploração da força de trabalho, nem tampouco, que não sejam reversíveis em uma conjuntura de crise, o que parcialmente passa a ocorrer a partir da década de 80, acompanhando os crescentes fluxos de circulação global de capital de empréstimo e o que Duménil \& Lévy (2005:86) denominam de "novo poder financeiro".

As instituições reconhecidas como de bem-estar social são necessárias ao poder de classe. Poulantzas (1985:212-213) pondera que a diversidade de compromissos sociais que o Estado assume seria função de dois aspectos: i) a reprodução da dominação de classe a longo prazo, mesmo que em certos períodos seja necessário impor sacrifícios materiais a setores das classes dominantes; ii) a luta de classes se impõe enquanto força específica; dependendo as funções sociais do Estado diretamente da intensidade da mobilização popular. As mudanças que se impõem institucionalmente, mesmo aquelas cuja consecução se deram via pressão dos setores populares se tornam parte da dinâmica capitalista, contanto que sejam assimiláveis no ciclo de acumulação e não contraditórias com as condições de equalização da taxa de lucro e de concorrência entre os capitais. ${ }^{11}$

As relações de controle são tanto coercitivas quanto ideológicas. Marx \& Engels na "Ideologia Alemã" (1984:56) apontaram para a importância deste aspecto, ao observarem que a classe, força material dominante na sociedade, é, ao mesmo tempo, sua força intelectual dominante. O predomínio ideológico da classe dominante sobre a classe subalterna na sociedade civil, parece se manifestar tanto na forma de repressão e poder militar, mas também enquanto capacidade de convencimento ideológico e subordinação consentida aos seus interesses dominantes.

Esse processo de ganhar corpos e almas se dá mediante uma ampla rede de instituições de controle e produção ideológica, desde a escola até as diversas mídias. Esses fatores se apóiam em uma base de legitimação social assentada na relação salarial.

A hegemonia não é fruto de um mero derivativo superestrutural do predomínio econômico e social, e sim resultado de permanentes atuações de um conjunto variado de agentes que se destinam a criar ou reforçar a base legitimadora da sociedade ${ }^{12}$. Carnoy (1986:99) pondera que o consentimento da sociedade como um todo aos interesses domi-

11 Conferir Poulantzas (1985:214).

12 Para interpretação neste sentido conferir Miliband (1972:221-2). 
nantes, se dá de fato mediante hegemonia ideológica, porém via agências que legitimam as relações sociais e aparelhos coercitivos do Estado.

Deve-se reforçar que uma percepção de poder hegemônico da classe proprietária dos meios de produção, necessariamente está ligada às forças de controle coercitivo da sociedade, não há como pensar as condições de domínio ideológico, separadas dos componentes institucionais destinados ao processo de repressão. Gramsci (apud Carnoy 1986:99) estabelece que o "Estado é o complexo das atividades práticas e teóricas com o qual a classe dominante não somente justifica e mantém a dominação como procura conquistar o consentimento ativo daqueles sobre os quais ela governa", portanto os mecanismos de coerção, controle e convencimento são formas interligadas no Estado capitalista. ${ }^{13}$

Lênin (1985) em diversas passagens de $O$ Estado e a Revolução reforça a idéia de Engels (2002) do "Estado enquanto força de repressão" de uma classe dominante sobre as demais. Modernamente os autores marxistas passam a utilizar uma dupla expressão que denota um conteúdo próximo, porém mais relativo: controle e legitimação. O primeiro termo controle reflete mais claramente a noção de repressão enquanto imposição coercitiva policial ou militar; o segundo termo legitimação reflete a noção desenvolvida por Gramsci de hegemonia. A sociedade capitalista contemporânea necessita de um crescente aprimoramento das forças de repressão internas, seja pela incapacidade estrutural do sistema de incluir crescentes parcelas da população no mercado de trabalho, reforçando a marginalidade e formas, mais ou menos, escusas de sobrevivência ${ }^{14}$; seja pela repressão às forças organizadas dos trabalhadores.

\section{Gastos estatais bélicos e militares}

Uma das características mais marcantes do capitalismo central deste século será o crescimento da indústria bélica, cujo poder chega a desenvolver no caso dos EUA, por exemplo, um autêntico Estado militarista, isso porque o principal demandante dessa indústria é o Estado, cuja contraposição é a crescente dotação de recursos necessários ao seu financiamento, como pode ser visto na Tabela I abaixo. A relação entre a dívida estatal e a guerra sob o capitalismo parece umbilical, por mais que desde meados do século XX outros fatores tenham passado a condicionar o déficit público nas economias centrais.

13 Para Carnoy (1986:110) Gramsci desenvolveu a teoria da hegemonia da classe dominante como complemento a uma teoria do Estado coercitivo de verniz leninista.

14 Vidal (2003:146) nos fornece a impressionante estatística retirada do USA Today, de que 6,6 milhões de adultos ( $3 \%$ da população adulta) [estadunidense] estão na cadeia ou em ' reabilitação'. 
TRINDADE, J. A dinâmica dos gastos estatais numa perspectiva...

TABELA I - EVOLUÇÃO DOS DISPÊNDIOS GOVERNAMENTAIS NOS ESTADOS UNIDOS (EM \%)

\begin{tabular}{llllllll}
\hline \multicolumn{1}{l}{ Todos os Níveis de Governo } & & & & & & & \\
\hline \multicolumn{1}{l}{ como Percentagem dos Dispêndios Totais } & 1902 & 1927 & 1940 & 1950 & 1960 & 1970 & 1973 \\
\hline & 20,8 & 11,8 & 11,8 & 36,0 & 38,0 & 28,2 & 22,9 \\
1. Relacionados com a defesa & 79,2 & 88,2 & 88,2 & 64,0 & 62,0 & 71,8 & 77,1 \\
2. Civis & 100,0 & 100,0 & 100,0 & 100,0 & 100,0 & 100,0 & 100,0 \\
3. Total & 1902 & 1927 & 1940 & 1950 & 1960 & 1970 & 1973 \\
\hline Como Percentagem do Produto Nacional Bruto & 1,5 & 1,2 & 2,1 & 8,3 & 10,3 & 9,1 & 7,2 \\
\hline & 5,8 & 9,2 & 15,5 & 14,8 & 16,7 & 23,1 & 24,3 \\
13. Relacionados com a defesa & 0,5 & 0,7 & 2,5 & 2,4 & 4,9 & 8,0 & 9,3 \\
14. Civis & 1,3 & 2,3 & 2,8 & 3,4 & 3,7 & 5,7 & 5,8 \\
15. Bem-estar social & 0,9 & 1,0 & 1,0 & 0,9 & 1,3 & 1,7 & 1,4 \\
16. Educação & 1,0 & 2,4 & 5,4 & 3,5 & 3,3 & 3,5 & 2,7 \\
17. Serviços civis & 1,0 & 2,2 & 2,6 & 1,6 & 2,0 & 1,9 & 1,7 \\
18. Desenvolvimento econômico & 0,1 & 0,2 & 2,8 & 1,9 & 1,3 & 1,6 & 1,1 \\
18.1 Transportes & 0,9 & 0,5 & 0,7 & 0,5 & 1,5 & 2,2 & 2,6 \\
18.2 Outros & 0,5 & 1,4 & 1,6 & 1,7 & 1,5 & 1,5 & 1,4 \\
19. Administração geral & 0,0 & 0,0 & 0,0 & 1,5 & 0,4 & 0,3 & 0,3 \\
20. Juros & 0,6 & 0,8 & 1,5 & 0,9 & 0,0 & 0,3 & 0,7 \\
21. Ajuda e relações internacionais & 7,3 & 10,4 & 17,6 & 23,1 & 27,0 & 32,2 & 31,5 \\
22. Itens diversos & & & & & & \\
23. Total & 1,0 &
\end{tabular}

Fontes: 1902-1973: Musgrave \& Musgrave (1980:115).

Obs: O "Survey of Current Business" publicou essas séries com este detalhamento até o ano de 1973 .

Existe uma intima ligação entre militarismo e expansão imperialista enquanto componente do desenvolvimento capitalista. Lênin (1985b) ao descrever o imperialismo como lógica econômica e política do capitalismo do século XX centrou sua análise no domínio das fontes de matérias-primas e na garantia de mercados importadores. Desde então a dinâmica histórica demonstra o quão longe iria a disputa entre Estados nacionais em defesa das bandeiras dos específicos interesses de seus capitais.

Deve-se notar que a manutenção do sistema bélico/militar se faz possível no interior da dinâmica de acumulação, com um fluxo permanente de valores em expansão, capaz de financiar os crescentes gastos do Estado com a maquinaria de guerra. A indústria bélica conduz sua produção tendo como grande demandante o Estado, cuja capacidade de absorção desta oferta produtiva vincula-se à receita total disponível em 
cada período, função da receita fiscal e da oferta de capital de empréstimo que resulta no endividamento estatal.

Os gastos estatais garantem o processo de acumulação do setor bélico da economia. Deste modo o valor-produto $(\mathrm{v}+\mathrm{m})$ produzido por estas indústrias requer fatias crescentes da receita estatal. Por outro lado, tais indústrias adquirem meios de produção do DI e pagam força de trabalho que realiza parcela dos valores de uso (meios de consumo) produzidos pelo DII. Enquanto o capital investido na produção de armamentos não representar uma descapitalização dos Departamentos I e II manter-se-á a capacidade produtiva desse setor destrutivo. ${ }^{15} \mathrm{Com}$ o crescimento do setor bélico e a crescente realização da sua produção por parte do Estado, a capacidade fiscal se exaure, sendo crescente a necessidade do financiamento via endividamento público.

A atual dinâmica capitalista, principalmente em relação aos EUA, reveste-se da condição particular de importância que toma a indústria bélica em relação à economia como um todo. O estudo já antigo, mas bastante ilustrativo, de Cook (1975:160) faz referência ao grande nível de dependência econômica de vinte e dois dos cinqüenta Estados norteamericanos em relação às despesas militares.

Segundo Hobsbawm (1995:247) 7\% do titânico PIB americano eram destinados às despesas de guerra em meados da década de 80 . $O$ grande enredamento da economia capitalista com seu setor bélico converge para um aspecto especificamente importante para a questão da dívida pública. Essa indústria não reproduz elementos materiais necessários ao capital produtivo, eliminando do mercado, por conta do seu crescimento, uma parcela cada vez maior de meios reprodutivos essenciais. Esse fato produz uma pressão sobre outros setores da economia e sobre a balança comercial, mediante a importação de meios produtivos de outros países. Na medida em que em grande parte a receita dessa indústria bélica é função quase exclusiva da demanda estatal, sua expansão passa a ser função da elevação dos gastos estatais. Deste modo é compreensível que frente à restrição fiscal, a expansão da divida pública seja o meio de garantir o financiamento crescente desses gastos excêntricos do Estado capitalista.

\section{Conclusão: os gastos estatais vistos em sua globalidade}

Após considerarmos os gastos do Estado em suas diversas e possíveis rubricas, podemos observar que mesmo sendo este uma totalidade complexa, abrange dois tipos específicos de instituições:

15 Conferir análise de Mandel (1982:212-53) e Mattick (1980:56-63). 
i) As mais flexíveis e sujeitas à influência de diversos setores sociais, o que configura a "periferia" do Estado, cujas funções econômicas típicas seriam aquelas voltadas tanto a suprir necessidades coletivas, quanto os gastos necessários aos capitais em geral.

ii) O núcleo duro do Estado, onde se localiza tanto as funções repressivas e militares, quanto as monetárias e de controle das finanças do Estado. Nestes setores vale a presença "afinada" com os interesses do capital em geral e dos segmentos dominantes do mesmo. Desse modo, o Estado ao controlar o padrão monetário o faz em conformidade com as condições de expansão da acumulação capitalista e as instituições do Estado destinadas a tais funções são as menos flexíveis ou passíveis de influência por parte de setores sociais que não o da fração dominante da classe proprietária.

A endogenia do Estado não permite que ele atue ilimitadamente sobre os ciclos de reprodução. Sua capacidade financeira e estrutura de gastos são limitadas pelas flutuações das taxas de lucro cujas modificações rítmicas estão na dependência de um conjunto de fatores próprios ao núcleo das relações de produção capitalistas. As intervenções do Estado são, no essencial, intervenções a posteriori e restritas, que tratam de qualquer maneira as conseqüências e os sintomas do processo econômico e que se esforçam em regularizar por reações-reflexas, as contradições econômicas (Poulantzas, 1985:222).

As contradições do financiamento do Estado capitalista naturalmente se relacionam aos limites da intervenção estatal. Lembra corretamente Poulantzas (1985:220-21) quanto aos limites estruturais da intervenção estatal que o fim da ideologia keynesiana se deu justamente pela inevitável condição estrutural de crise do sistema. Na medida em que o Estado é um componente sustentado pelos fluxos de renda provenientes do sistema de reprodução do capital, este não pode por si mesmo, equacionar as crises, por mais que atue, conforme suas políticas econômicas, na gestão política das condições de crise.

A intervenção do Estado pode muito restritamente atuar como recurso de contra tendência à queda da taxa média de lucro. Considerando, principalmente, os gastos na forma de investimento social enquanto um componente utilizável reprodutivamente pelo capital, a maior e melhor disponibilidade diminuem as necessidades de capital fixo por parte dos capitais particulares, atuando sobre a taxa de lucro via diminuição da composição orgânica de capital. ${ }^{16} \mathrm{Na}$ medida em que a crise expressa,

16 Matematicamente a relação exposta pode ser vista na formula geral: l'=m/c+v, dividindo-se todos os fatores da direita por v, obtém-se: $l^{\prime}=\mathrm{m} / \mathrm{q}+1$, onde l' é a taxa de lucro, m'é a taxa de mais-valia e $\mathrm{q}$ a composição orgânica do capital (c/v). Uma diminuição de q é possível pelo menor uso de capital constante (c), o que se viabiliza com o uso menos intensivo de capital fixo permitido pelos gastos estatais. 
como disserta Mattick (1980:203), que o nível de rentabilidade do capital é insuficiente para garantir a acumulação, e que o Estado ao desempenhar suas funções requer parcela da mais-valia na forma de impostos, conclui-se que este agente econômico não pode influir enquanto força definitiva na tendência secular de declínio da taxa de lucro.

O Estado requer para financiar seus gastos uma parcela da mais-valia produzida no sistema de reprodução capitalista e, por outro lado, os gastos estatais destinam-se a mero consumo, não compondo elementos da acumulação, na medida em que seus dispêndios são partes do consumo improdutivo da sociedade. Deste modo é correto assinalar que os gastos bélicos, como de resto todos os gastos estatais que não são cobertos pela produção estatal [isto é empresas estatais] estão exclusivamente desde o ponto de vista social na esfera do consumo e não da acumulação.

Mattick (1980:82) reforça a importante diferenciação entre o entendimento marxista quanto aos gastos estatais e a compreensão defendida pelas correntes keynesianas. Assinala aquele autor, que independente de quantos empregos e renda possam gerar, o produto final da produção induzida pelo Estado, como obras públicas de caráter útil ou de desperdício, isso não aumenta a massa de mais-valia. Os gastos estatais ao absorverem mais-valia ou capital de empréstimo, tornando essa massa de valor renda despendida, possibilitam no máximo, formas de consumo social distintos daqueles que haveria se não houvesse sua específica atuação. Nesse sentido, esses gastos podem de fato ser mais ou menos interessantes sob o ponto de vista da sociedade como um todo, porém, sob o ponto de vista da acumulação capitalista representam unicamente consumo improdutivo.

\section{Referências}

BARROW, Clyde (2000). "The Marx problem in Marxian State Theory." Science \& Society, 64(1):87-118.

CARNOY, M. (1986). Estado e teoria política. Campinas, SP: Papirus.

COOK, Fred (1975). O Estado Militarista. Rio de Janeiro: Editora Civilização Brasileira.

De BRUNHOFF, Suzanne (1978). A moeda em Marx. Rio de Janeiro: Paz e Terra.

DUMÉNIL, G. \& LÉVY, D. (2003). Superação da crise, ameaças de crise e novo capitalismo. In: CHESNAIS, F. et al. Uma nova fase do capitalismo? São Paulo: Xamã.

DUMÉNIL, G. \& LÉVY, D. (2005). “O neoliberalismo sob a hegemonia 
TRINDADE, J. A dinâmica dos gastos estatais numa perspectiva...

norte-americana.” In: CHESNAIS, F. A finança mundializada. São Paulo: Boitempo.

ENGELS, F. (2002) A origem da Família, da Propriedade privada e do Estado. São Paulo: Centauros Editora.

FIGUEIREDO, Mario João. (2003) A configuração econômica do estado na sociedade capitalista contemporânea. Tese de Doutoramento, UFPR.

FINE, B \& HARRIS, L. (1976) "State expenditure in advanced capitalism: a critique." New Left Review 98.

FINE, B. (1981 ). Para reler O Capital. Rio de Janeiro: Zahar.

FOLEY, D. (1990). "State expenditure from a Marxist perpective." In: BAKER, S. H. \& ELLIOTT, C. S. Readings in Public Sector Economics. Massachusetts: D. C. Heath and Company.

GOUGH, Ian. (1975). "State expenditure and capital." New Left Review 92:53-92.

HIRSCH, Joachim. (1990). "O problema da dedução da forma e da função do Estado burguês.” In: REICHELT, H. et al. A Teoria do Estado: materiais para a reconstrução da teoria marxista do Estado. Rio de Janeiro: Tempo Brasileiro.

HOBSBAWM, E. (1995). Era dos Extremos: O breve século XX (1914-1991). São Paulo: Companhia das Letras.

JESSOP, Bob. The Capitalist State. Oxford: Martin Robertson; Nova York: Nova York University Press.

LENIN, V. I. (1985). Imperialismo, fase superior do capitalismo. São Paulo: Global.

LENIN, V. I. (1986). "Sobre o Estado." In: Obras Escolhidas. Lisboa: Edições Avante, tomo 4.

MANDEL, E. (1982). O capitalismo tardio. São Paulo: Abril Cultural.

MARX, K. (1985). Capítulo VI Inédito de O Capital: resultados do processo de produção imediata. São Paulo: Editora Moraes, 1985.

MARX, K. (1983). Contribuição à crítica da economia política, 2. ed. São Paulo: Martins Fontes.

MARX, K. (1987). O Capital: crítica da economia política, v. I, II e III. Rio de Janeiro: Civilização Brasileira/DIFEL, 1981.

MATTICK, Paul. (1975). Marx y Keynes: los limites de la economia mixta. México: Ediciones Era.

MATTICK, Paul. (1980). Crítica de la teoría económica contemporánea. México: Ediciones Era.

MILIBAND, R. (1972). O estado na sociedade capitalista. Rio de Janeiro: ZAHAR Editores.

MOLLO, Maria de Lourdes (1990). "Estado e Economia: o papel monetário do Estado." Estudos Econômicos, São Paulo 20(1):87-100. 
MONIZ BANDEIRA, L. (2005). Formação do Império americano: da guerra contra a Espanha à guerra no Iraque. Rio de Janeiro: Civilização Brasileira.

MUSGRAVE, R. \& MUSGRAVE, P. (1980). Finanças públicas: teoria e prática. Rio de Janeiro: Campus.

O'CONNOR, J. ( 1977). USA: A crise do Estado capitalista. Rio de Janeiro, Paz e Terra.

POULANTZAS, N. (1977) "As transformações atuais do Estado, a crise política e a crise do Estado." In: POULANTZAS, N. (org.). O Estado em crise. Rio de Janeiro: Edições Graal.

POUlanTZAS, N. (1985). O Estado, o poder, o socialismo. Rio de Janeiro: Edições Graal.

SCHÄFER, G. (1990). “Alguns problemas decorrentes da relação entre dominação 'econômica' e 'política'." In: REICHELT, H. et al. A Teoria do Estado: materiais para a reconstrução da teoria marxista do Estado. Rio de Janeiro: Tempo Brasileiro.

SCHUMPETER, J. (1968). “Capitalismo en el mundo de posguerra.” In: Ensayos de Joseph A. Schumpeter. Barcelona: Oikos-tau.

SHAIKH, A. (1988). "Centralização e concentração do capital." In: BOTTOMORE, T. (editor). Dicionário do Pensamento Marxista. Rio de Janeiro: Zahar.

SMITH, A. (1988). A riqueza das nações (volume III). São Paulo: Nova Cultural.

STUDENSKI, P. \& KROOSS, H. (1963). Financial history of the United States. New York: McGraw-Hill.

TAYLOR, Philip E. (1960) Economia de La hacienda publica. Madrid: Aguilar.

TEIXEIRA, Francisco (1995). Economia e filosofia no pensamento político moderno. São Paulo: Pontes.

VIDAL, Gore (2003). Sonhando a Guerra. Rio de Janeiro: Nova Fronteira. 